\title{
Effect of Fluid Flow Characteristics on Migration of Nano-Particles in Porous Media
}

\author{
Saeed Sourani1, Mohammad Afkhami², Yousef Kazemzadeh ${ }^{3}$, Hooman Fallah4 \\ ${ }^{1}$ Department of Petroleum Engineering, Shiraz University, Fars, Iran \\ ${ }^{2}$ Department of Petroleum Engineering, Islamic Azad University of Marvdasht, Fars, Iran \\ ${ }^{3}$ Department of Petroleum Engineering, Islamic Azad University of Lamerd, Fars, Iran \\ ${ }^{4}$ Department of Petroleum Engineering, Islamic Azad University, Firoozabad Branch, Firoozabad, Fars, Iran \\ Email: Soorani.saeed@yahoo.com, Mohammad.afkhami1@gmail.com, yusefkazemzade@yahoo.com, \\ Hoomanfallah2@gmail.com
}

Received 2 May 2014; revised 27 May 2014; accepted 20 June 2014

Copyright (C) 2014 by authors and Scientific Research Publishing Inc.

This work is licensed under the Creative Commons Attribution International License (CC BY).

http://creativecommons.org/licenses/by/4.0/

(c) (i) Open Access

\begin{abstract}
Inter-particle and molecular forces are of most important forces affecting fines migration. Investigating the impact of these types of forces requires information about electrical properties of constitutive component and Nano-sized solids. Surface potential is a well-known parameter, which can be used to measure aforementioned forces. The force balance among electrical, gravity, drag and buoyance forces tracing on a particle can be estimated using fluid properties and physical properties of reservoir such as surface potential, pore size distribution and fine size distribution. The task is to set these forces at conditions that fine migration does not take place. This paper investigates the impact of several parameters that could influence pertinent forces. Effect of ionic strength of flowing fluid is taken into account to evaluate Debye length that determines double layer forces. The impact of injection rate on a parameter named erosion number is also studied. The results of this study show that how introducing salts and injection rate can affect stability of fines on their locations.
\end{abstract}

\section{Keywords}

Fines Migration, Reservoir Damage, Inter-Particle Forces, Electrical Double Layer, Injection Rate

\section{Introduction}

Water injection in hydrocarbon reservoirs for EOR purposes generally leads to formation damage. Several mechanisms of this phenomenon have been explained by different authors [1]-[3]. Formation damage could be de- 
fined as formation permeability reduction. Formation damage reduces production and injectivity of formation. Figure 1 [4] shows a case in which injectivity of an Iranian oil field reduced as a result of fine migration.

Several parameters play role in the process of formation damage. These parameters can be classified in two categories: properties of porous media and the characteristics of flowing fluids. Pore size distribution, pore continuity, concentration and size distribution of fines are the parameters of the former category. Injection rate, salinity and $\mathrm{pH}$ of water (as a displacing phase) are the parameters of the latter one. Investigating the parameters of the first group is out of scope of this study. Therefore, ionic strength (concentration and ionic valence) and injection rate (as a function of velocity of fluid) are studied as two important parameters determining behavior of fine particles in presence of a liquid phase.

\subsection{Inter Particle Forces}

Some particles in reservoir porous media are very small so that their static and dynamic conditions can be controlled by surface phenomena. These types of forces include London-Van der Waals attraction, electrostatic repulsion, Hydration, Hydrophobic and several other forces. In this study, only two major inter-particle forces; i.e. London-Van der Waals and electrostatic double layer are focused on. The force balance of these inter-particle forces could be shown as bellow:

$$
F_{e}=F_{L V A}+F_{D L R}
$$

where, subscripts of LVA and DLR stand for Attractive London-Van der Waals and Repulsive Double Layer forces, respectively. And:

$$
F=f(x, \gamma, T, \epsilon, \mathrm{pH}, r)
$$

where $x, \gamma, T, \epsilon, \mathrm{pH}$ and $r$ are the distance from surface of solid, ionic strength, temperature, permittivity, $\mathrm{pH}$ of solution, and radius of particles, respectively. Also [5]:

$$
\gamma=\sum_{i} n_{i} z_{i}^{2} \text { And } \epsilon=\varepsilon \varepsilon_{0}
$$

where, $n$ and $z$ are number and valency of $i^{\text {th }}$ ion, respectively. $\varepsilon$ is dielectric constant and $\varepsilon_{0}$ is permittivity of vacuum.

\subsubsection{Electrostatic Forces}

One of the surface forces controlling behavior of Nano-sized materials in porous media results by ion dispersion in a manner that two layers are formed in the liquid phase that surrounds the solid; one interior molecular layer with a charge opposite of solid surface charge, with an exterior layer made by distribution of ions with a charge opposite to the first layer. The second layer fades away with increasing distance from the solid surface [5]. These two layers are schematically shown in Figure 2. It should be noted that the whole solution is neutral; however, this type of ion distribution makes the liquid to have electrical potential in points close to the solid surface.

Instantly beyond the surface of a charged particle, opposite ions are attached and move as the particle moves (stern layer). Then, ions with the same sign as surface of particle slip over the first layer (slipping or diffuse layer) and their concentration decrease with distance from solid surface.

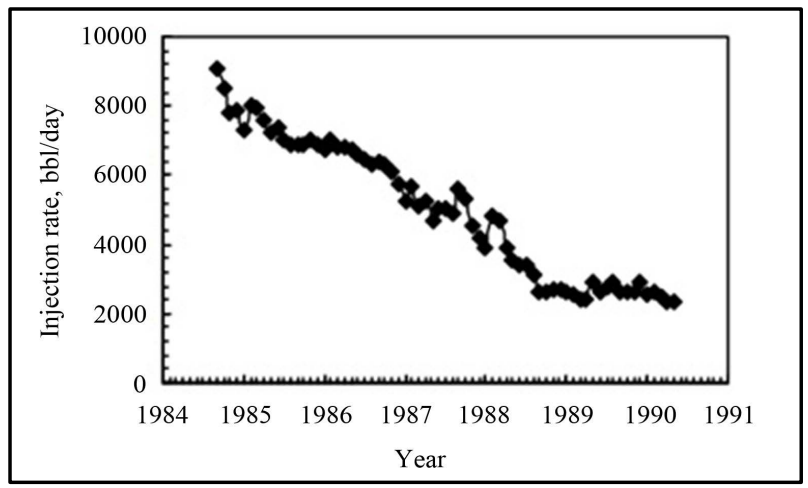

Figure 1. Water injection history in Iranian Siri oil field. 


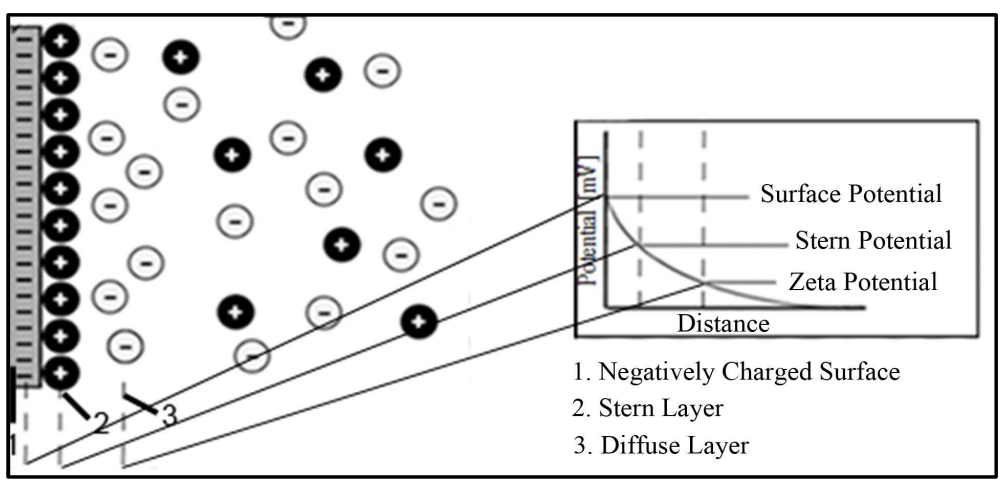

Figure 2. Schematic of a double layer in vicinity of a negatively charged surface and ion distribution of negative and positive ions around the surface. The induced potential decreases vs. distance from the face of charged plate.

Formation of these two layers leads to definition of double layer and double layer force. This force can be estimated using surface potential. Surface potential could be estimated by a parameter named zeta potential that is an electrical potential in a certain distance from surface of solid. Zeta potential is estimated by experimental methods. Here, the surface charge value was assumed to be in a normal range. Particle is considered to be made of the same matter that makes reservoir rock. Thus, the potential of particle surface is equal to pore wall potential because they are both surrounded by a same liquid.

Two assumptions are made in this study to determine electrostatic forces in porous media include:

- The force between a particle and pore wall considered as a force between sphere and plate. Potential of sphere and plate are constant. This force can be measured by Equation (2) [6]. Figure 3 shows a schematic indication of ion distribution that causes the related forces.

- All pores are wide enough that double layers induced by two close walls do not overlap; i.e. zeta potential of solution is generated due to one surface charge.

$$
\begin{aligned}
& F_{D L R}=\frac{\epsilon r_{p}}{4}\left[2 \psi_{01} \psi_{02}\left(\frac{1+\exp (-\kappa x)}{1-\exp (-\kappa x)}\right)+\left(\psi_{01}^{2}+\psi_{01}^{2}\right) \ln (1-\exp (-2 \kappa x))\right] \\
& \kappa=\sqrt{\frac{e^{2} \gamma}{\varepsilon k_{B} T}}
\end{aligned}
$$

where, $r_{p}$ is particle radius, $k_{B}$ is Boltzmann's constant, $e$ is electron potential, $\psi_{01}$ and $\psi_{02}$ refer to surface potential of plate and sphere, and $\kappa$ is the reciprocal Debye length.

According to the fact that surface charge depends on ionic strength and $\mathrm{pH}$, therefore electrical forces and properties of double layer should be functions of these two parameters as well. Subsequently, the possibility of releasing fines from a wall would be strongly affected by ionic strength and $\mathrm{pH}$.

\subsubsection{London-Van der Waals Force}

This force is due to coupling of electron clouds around adjacent atoms. The previous assumption of considering fines as spheres and pore wall as plates is also made here. The force between a sphere and a plate can be calculated using Equation (3) [7].

$$
F_{V D A}=A \frac{r_{p}}{6 x}
$$

where, $A$ is the Hamaker constant; which is a function of permittivity of media, temperature, volume and molecule types. Values of $A$ is tabulated in several texts [8]. Hamaker constant used in this study is an average for reservoir rock minerals and estimated about $5 \times 10^{-20} \mathrm{j}$.

\subsection{Migration of Fines in Porous Media}

Fluid flow through the pores makes several forces that could impact the movement of fines in the media. As 
shown in Figure 4 these forces are: 1 ) electrical forces, $F_{e} ; 2$ ) drag force; $F_{d}$, 3) lifting (buoyance) force, $F_{1}$, and 4) gravity, $F_{g}[9]$.

Erosion number can be defined as Equation (4):

$$
\sigma=\frac{\left(F_{D L R}+F_{l}\right) l_{n}+F_{d} l_{d}}{\left(F_{V D A}+F_{g}\right) l_{n}}
$$

where $l_{n}$ and $l_{d}$ are normal and drag levers as shown in Figure 4 . When the erosion number reaches unity, the particle is in an unstable condition and increasing the numerator of Equation (4) leads to releasing the particle. When this number is lower than unity the fine grips to the surface. These forces should act in a way that particle do not release from pore surface. i.e. $\left(F_{D L R}+F_{l}\right) l_{n}+\left(F_{d}\right) l_{d}<\left(F_{V D A}+F_{g}\right) l_{n}$.

$E_{D L R}$ and $E_{V D A}$ can be obtained using Equations (2) and (3), respectively. Other forces are determined as follows.

\subsubsection{Drag Force [10]}

For low amounts of Reynolds number (i.e. $\mathrm{Re}<1$ ) the drag force predominated by frictional force. Then:

$$
F_{d}=\frac{\pi \mu \omega r_{p} U}{\varphi\left(H-h_{c}\right)}
$$

where, $\mu$ is water viscosity, $\omega$ is proportionality factor (in the range of $10-60$ ), $H$ and $h_{c}$ are the hight of pore and deposited particles on the pore wall, respectively. $h_{c}$ is asseumed to be equal to only one layer of fine particle $\left(2 r_{p}\right)$. $U$ and $\varphi$ are the velocity of fluid and porosity, respectively.

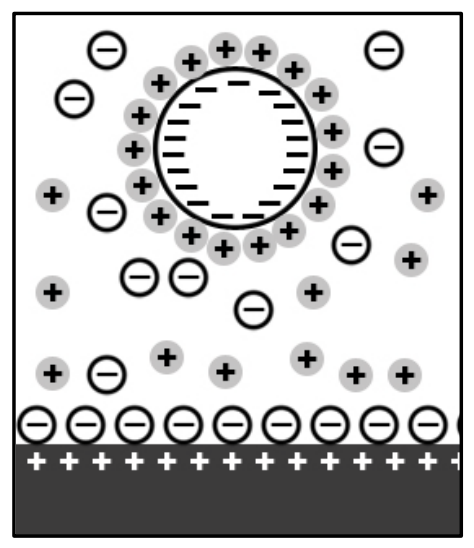

Figure 3. Ion distribution that causes the Van der Waals Atraction and double layer repulsion forces between suspended particle and pore wall.

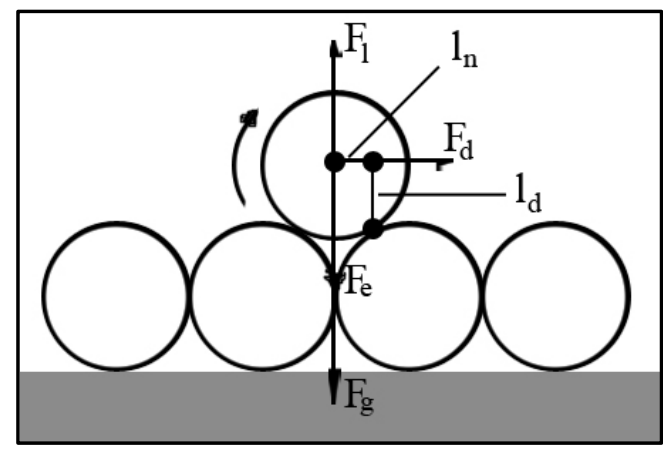

Figure 4. An indication of forces acting on a Nano-sized particle as a result of fluid flow through porous media: Electrical force $\left(F_{e}\right)$, Lifting force $\left(F_{1}\right)$, Drag force $\left(F_{d}\right)$, Gravity force $\left(F_{g}\right)$ and normal $\left(l_{n}\right)$ and drag $\left(l_{d}\right)$ levers (Figure from [8]). 


\subsubsection{Lifting Force [11]}

$$
F_{L}=89.5 r_{p}^{3} \sqrt{\frac{\rho_{w} \mu U^{3}}{\left(H-h_{c}\right)^{3}}}
$$

where $\rho_{w}$ is water density.

\subsubsection{Gravity Force}

$$
F_{g}=\frac{4}{3} \pi r_{p}^{3} g\left(\rho_{p}-\rho_{w}\right)
$$

where $g$ is gravitational constant and $\rho_{p}$ is density of the particle.

\section{Composition of Displacing Phase}

As can be seen from Equations (2) and (3), electrostatic double layer force is a function of ionic strength and fluid composition because of its dependency on Debye length, $\kappa$, and permittivity, $\epsilon$. Dependency of Van der Waals force on fluid composition is described by the Hamaker constant, which is a proportionality factor for forces caused by the transient induced dipoles associated with interatomic bonds [12]. Calculations made in this study are based on the data summarized in Table 1.

\section{Results and Discussion}

\subsection{Debye Length}

Debye Length is a function of ion concentrations and their valences. It changes with alteration of solution composition as is discussed in the following sections.

\subsection{Ionic Strength Effect}

Figure 5 shows the impact of valance and concentration on Debye length caused a charged solid. As can be seen, increasing valence of ions increases the Debye length (i.e. decreasing diffuse layer distance from surface of solid). This implies that density of ions close to the solid surface increases when valence increases.

According to the results of Figure 5 that shows increasing ionic strength increases Debye length, Figure 6 shows that by increasing salinity double layer force between the particle and plate decreases. This value is a function of valence of ions. It should be noted that, at very low concentrations the forces of different valences show different trend compared to the general trend (that the higher ionic strengths yield higher double layer repulsive). Another important point is that according to Equation (2) at lower concentrations (0.0037 for 1:1, 0.0044 for $2: 2,0.0023$ for 2:1, 0.0053 for 3:1, and 0.0023 for 3:2 solutions) the double layer force acts as an attractive force.

Table 1. Values of Parameters used in this study.

\begin{tabular}{cccc}
\hline Parameter & Value & Parameter & Value \\
\hline Surface Potential of Wall, $\psi_{01}[\mathrm{~V}]$ & 0.100 & Bulk Density of Solid, $\rho_{\mathrm{s}}\left[\mathrm{kg} / \mathrm{m}^{3}\right]$ & 2200 \\
Surface Potential of Fine, $\psi_{02}[\mathrm{~V}]$ & 0.100 & Porosity, [percent $] \Phi$ & 20 \\
Hamaker Constant, $A[\mathrm{j}]$ & $10^{-20}$ & Displacing Phase Velocity, $V[\mathrm{~m} / \mathrm{s}]$ & $2 \times 10^{-3}$ \\
Boltzmann Constant, $k_{B}[\mathrm{j} / \mathrm{k}]$ & $1.38 \times 10^{-23}$ & Particle Radius, $r_{p}[\mathrm{~m}]$ & $4 \times 10^{-7}$ \\
Permittivity of Media, $\varepsilon$ & 80 & Channel (pore) Height $[\mathrm{m}]$ & $1 \times 10^{-6}$ \\
Electron Charge, $e[\mathrm{C}]$ & $1.602 \times 10^{-19}$ & Salinity [molar] & $0-2$ \\
Temperature, $T[\mathrm{k}]$ & 268.15 & Ionic Valence & $1,2,3$ \\
Water Viscosity, $\mu_{w}[\mathrm{cp}]$ & 1 & Distance of Particle and Wall $[\mathrm{m}]$ & $10^{-10}$ \\
Water Density, $\rho_{w}\left[\mathrm{~kg} / \mathrm{m}^{3}\right]$ & 1000.1 & - & - \\
\hline
\end{tabular}




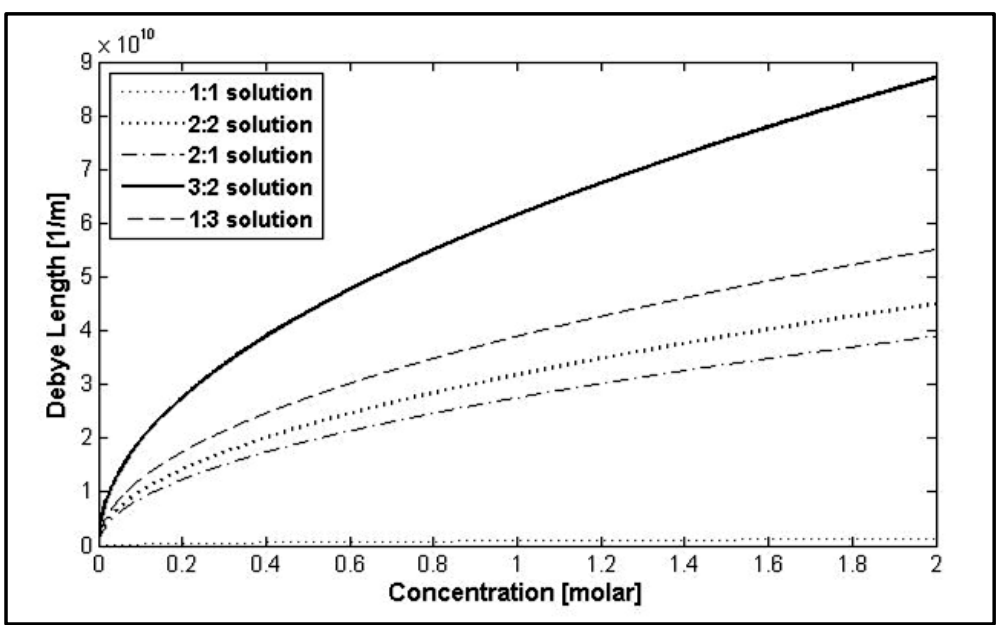

Figure 5. Effect of ionic Strength as a function of concentration and ionic valence on Debye length expressed as $k / \sqrt{\varepsilon_{s}} \quad[1 / \mathrm{m}]$.

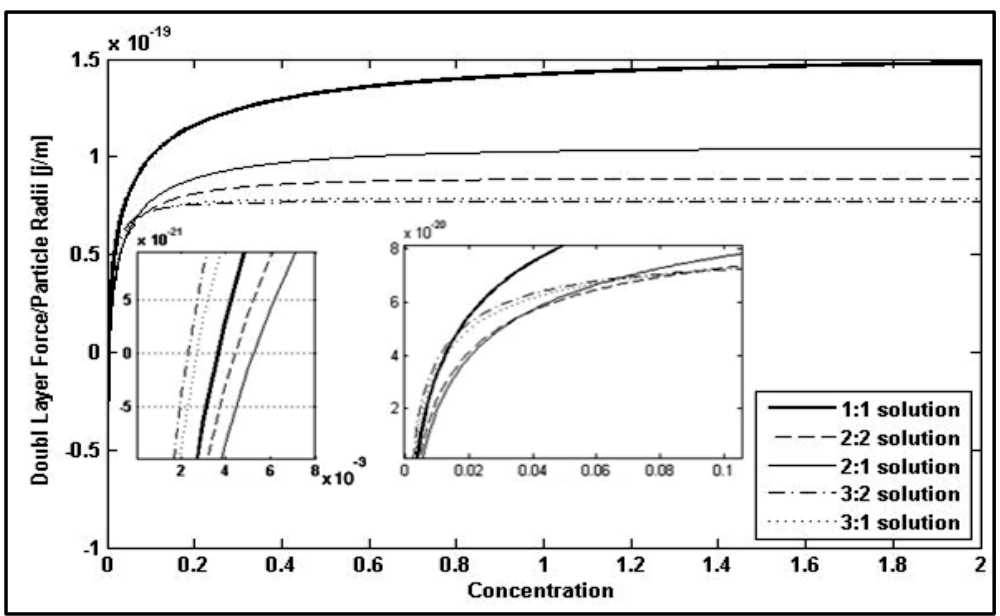

Figure 6. Effect of ionic strength on double layer forces; at very low concentrations the behavior is in contrary with the general trend.

\subsection{Distance between Particle and Pore Wall}

Finally, effect of distance between particle and plate is shown in Figure 7. This factor impacts entrapping of a moving particle to adsorb on pore wall and also releasing a particle according to its position on the wall.

\section{4. pH Effect}

$\mathrm{H}^{+}$and $\mathrm{OH}^{-}$are two potential determining components [5], which can be predominant to define potential of solid surface. According to some of wettability studies, charge of some materials is not a linear function of $\mathrm{pH}$. In experimental results of some researchers [6] [13] show that by increasing $\mathrm{pH}$, contact angle (as a function of zeta potential) reaches to a certain point and starts to alter its trend.

\subsection{Properties That Affect Fines Migration}

As explained by Equations (2) to (8), separation of a Nano-sized particle from the solid face of pore wall as a result of fluid flow (because of oil/gas production or injection processes) is predictable using Equation (4). In this work, changes of ionic strength (valence and concentration), fluid velocity (flow rate), and pore wall-fine spacing are studied. 


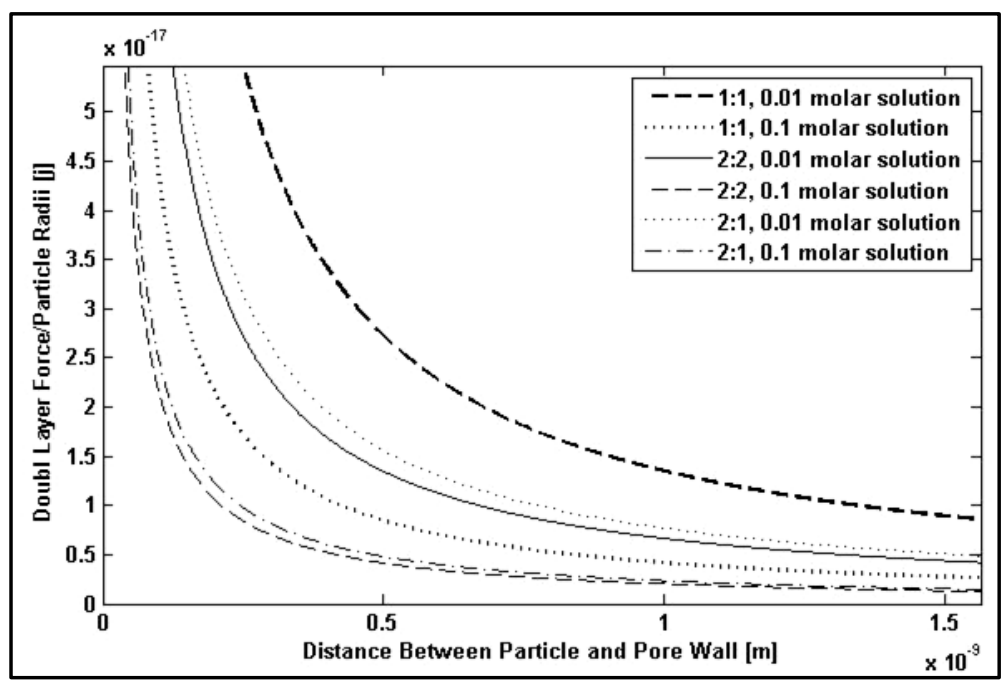

Figure 7. Decreasing double layer force by increasing distance from the charged surface.

Separation of a particle from a pore wall and its migration happens when erosion number approaches to unity (where the repulsive forces overcome the attractive forces). Double layer force is determined by Debye length, which is a function of ionic strength. Thus, changing salinity would affect erosion number and consequently impacts fines migration. Figure 8 shows effect of ionic strength on erosion number; constant parameters are those in Table 1.

Figure 9(a) to Figure 9(f) show the effect of velocity (injection rate) on erosion number in different ionic strengths. During injection processes, an important factor is to optimize injection rate to minimize formation damage caused by fines migration.

In these figures, the velocities under the interception line of erosion number vs. velocity curve in $\varepsilon=1$ are under the critical values and do not cause fines migration. Velocity is not a crucial parameter under the conditions in Figure 9(a) to Figure 9(f), since the curve is either bellow $\varepsilon=1$ (i.e. migration does not happen, even under high injection rate conditions; consider limited range of fluid injection velocity in pore scale) or above $\varepsilon=1$ (i.e. migration happens; presence of liquid causes separation of fine from pore wall, even if the liquid phase is under static condition). Figure 10 shows another case that in a critical velocity erosion number becomes more than 1 . This shows that in some conditions the slightest changes of injection rate (velocity) can cause fines migration and reservoir damages.

\section{Conclusions}

Inter-molecular forces have important roles in determining behaviors of material in different fields. The results of this study explain circumstances of fine separation from a solid surface that is defined as fine migration in porous media. This phenomenon could cause serious damage in hydrocarbon reservoirs due to blocking pores and permeability reduction.

There are several parameters that effect migration of fines. These parameters include reservoir formation characteristics and injected agent properties. Some of these affecting parameters such as ionic strength (ion valences and their concentrations), velocity of injected fluid, particle and pore wall spacing and their influences on discussed phenomena were studied in this paper. The impact of each parameter on the electrical properties of media and the resultant forces that could cause releasing of fines from a wall is summarized as follow:

- Debye length increases with ionic strength of solution. That is, the ions are concentrated around the charged face and decrease the distance between diffuse layer and solid face.

- Increasing Debye length reduces the double layer repulsion; it means that at higher ionic strengths, repulsion is lower. This implies that in unconsolidated reservoir with high concentration of fines that inclined to migrate, high salinity water should be injected to avoid reservoir damage.

- By balancing involved forces and definition of a quantity named erosion number that is a ratio of forces tend 


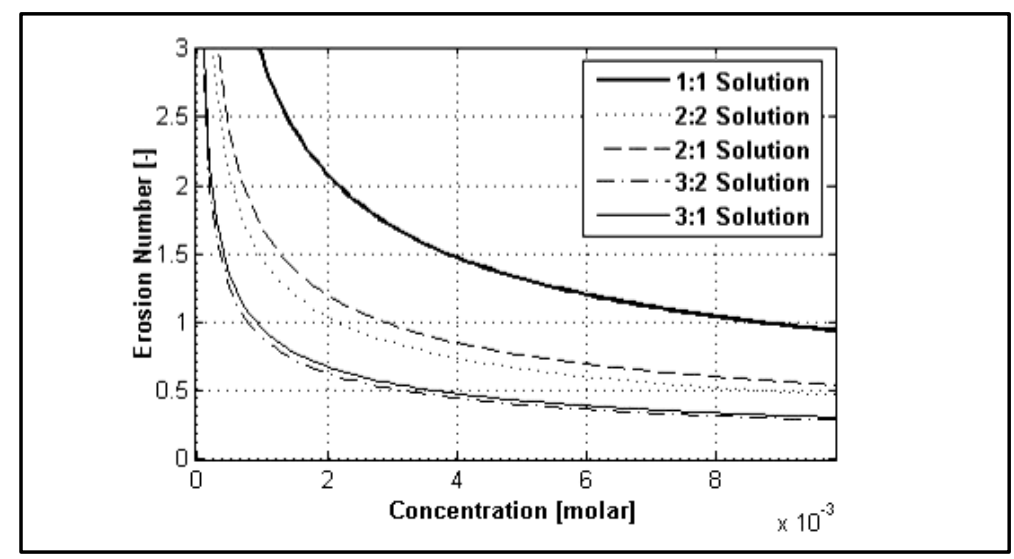

Figure 8. Erosion number change as a function of ionic strength. The values intersecting with $\varepsilon=1$ imply critical concentration.
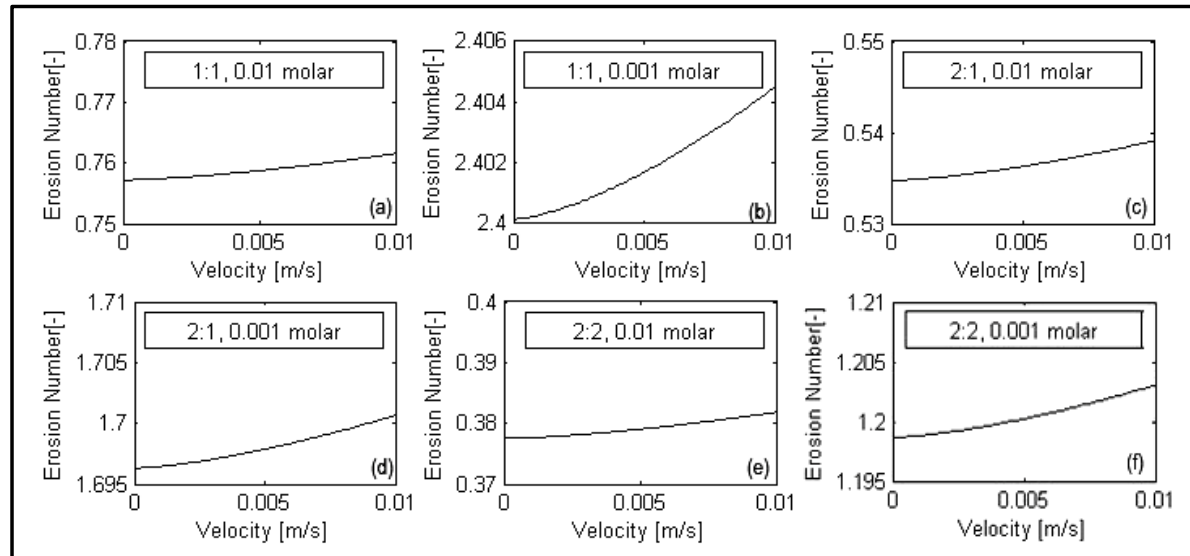

Figure 9. Erosion number changes as a function of velocity for different ionic strengths.

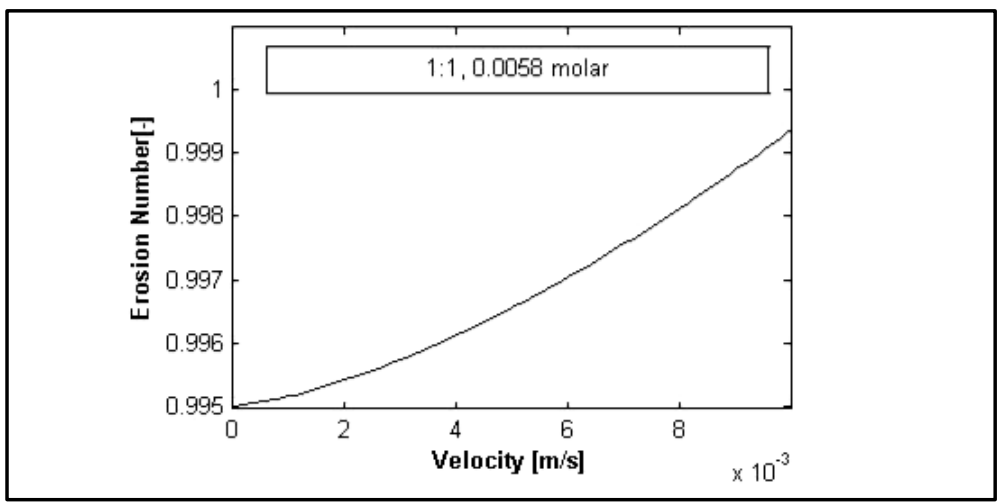

Figure 10. Velocity importance under a specific condition.

to separate a particle to the forces try to settle it, this is predictable that whether a particle will release from a surface of solid or not. The particle stands until the erosion number reaches to unity; i.e. separating forces overcome to the settling forces.

- Dependency of the introduced forces to different parameters causes the erosion number to be different for different reservoir conditions and different displacing fluid properties. As shown in the plots, though increasing fine size causes increase in double layer repulsive force, however, according to presence of other forces, fines migration decreases. 
- Injection rate is one of the most important parameters in EOR processes. The salinity of the displacing phase has also a key role in final recovery. Thus, to eliminate reservoir damages a study of injection rate and suitable salinity should be performed. The general trend is that by increasing the ionic strength the maximum allowable velocity increases.

\section{References}

[1] Bedrikovetsky, P., Furtado, C.A., de Souza, A.L.S. and Siqueira, F.D. (2007) Internal Erosion in Rocks during Produced and Seawater Injection. SPE 107513, SPE Europec/EAGE Annual Conference and Exhibition, London, 11-14 June 2007.

[2] Kwan, M.Y.M., Cullen, M.P., Jamieson, P.R. and Fortier, R.A. (1988) A Study of Fines Migration Related Permeability Damage in Extracted Cold Lake Heavy Oil Cores. 39th Annual Technical Meeting of the Petroleum Society of CIM, Calgary, 12-16 June 1988.

[3] Valdya, R.N. and Fogler, H.S. (1992) Fines Migration and Formation Damage: Influence of pH and Ion Exchange. SPE Production Engineering, 7, 325-330.

[4] Moghadasi, J., Jamialahmadi, M., Müller-Steinhagen, H., Sharif, A., Izadpanah, M.R., Motaei, E. and Barati, R. (2002) Formation Damage in Iranian Oil Fields. SPE 73781.

[5] Adamson, A.W. and Gast, A.P. (1997) Physical Chemistry of Surfaces, Chapter 5. A Wiley-Interscience Publication, 170.

[6] Takashi, S. (2009) Water Imbibition, Electrical Surface Forces, and Wettability of Low Permeability Fractured Porous Media. Ph.D. Thesis, Stanford University, Stanford.

[7] Ross, S. and Morrison, I.D. (1988) Colloidal Systems and Interfaces. John Wiley Publication, New York.

[8] French, R.H., Muèllejans, H., Jones, D.J., Duscher, G., Cannon, R.M. and Ruèhle, M. (1998) Dispersion Forces and Hamaker Constants for Intergranular Films in Silicon Nitride from Spatially Resolved-Valence Electron Energy Loss Spectrum Imaging. Acta Materialia, 46, 2271-2287. http://dx.doi.org/10.1016/S1359-6454(98)80008-6

[9] Zeinijahromi, A., Phuong, T.N. and Bedrikovetsky, P. (2011) Taking Advantage of Fines-Migration-Induced Formation Damage for Improved Waterflooding (Reservoir Simulation Using Polymer Flood Option). SPE 144009, SPE European Formation Damage Conference, Noordwijk, 7-10 June 2011.

[10] Bedrikovetsky, P., Furtado, C.A., De Souza, A.L.S. and Siqueira, F.D. (2007) Internal Erosion in Rocks during Produced and Seawater Injection. SPE 107513, SPE Europec/EAGE Annual Conference and Exhibition, London, 11-14 June 2007.

[11] Farajzadeh, R. (2004) Produced Water Re-Injection (PWRI) an Experimental Investigation into Internal Filtration and External Cake Build Up. M.Sc. Thesis, Delft University.

[12] Khilar, K.C., Vaidya, R.N. and Fogler, H.S. (1990) Colloidally-Induced Fines Release in Porous Media. Journal of Petroleum Science and Engineering, 4, 213-221. http://dx.doi.org/10.1016/0920-4105(90)90011-Q

[13] Hoeiland, S., Barth, T., Blokhus, A.M. and Skauge, A. (2001) the Effect of Crude Oil Acid Fractions on Wettability as Studied By Interfacial Tension and Contact Angles. Journal of Petroleum Science and Engineering, 30, 91-103. http://dx.doi.org/10.1016/S0920-4105(01)00106-1 
Scientific Research Publishing (SCIRP) is one of the largest Open Access journal publishers. It is currently publishing more than 200 open access, online, peer-reviewed journals covering a wide range of academic disciplines. SCIRP serves the worldwide academic communities and contributes to the progress and application of science with its publication.

Other selected journals from SCIRP are listed as below. Submit your manuscript to us via either submit@scirp.org or Online Submission Portal.
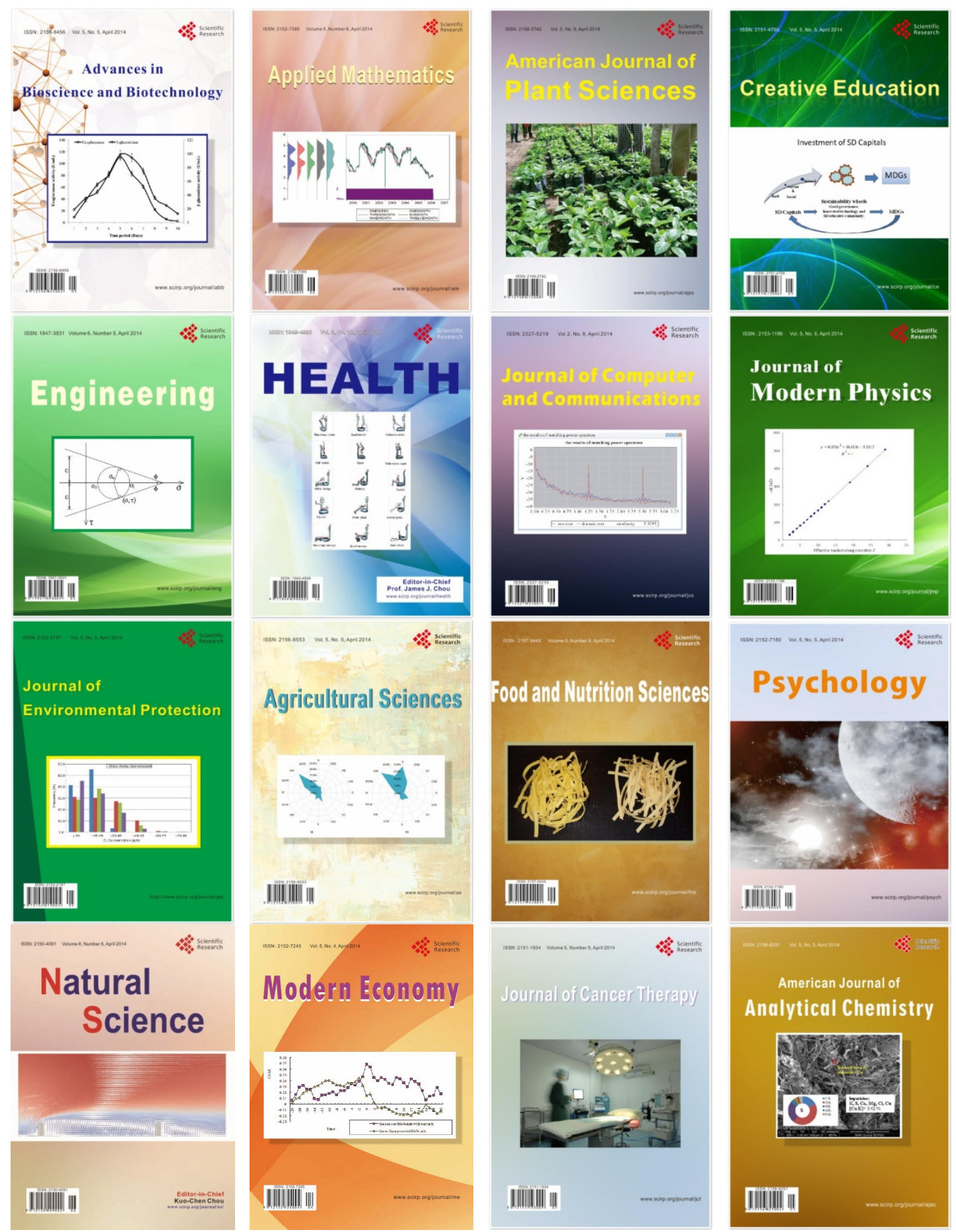